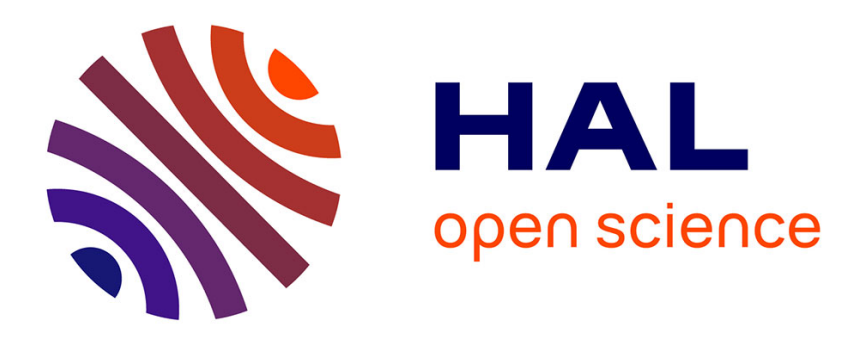

\title{
Vapour phase chemical transport properties of the cadmium telluride-iodine system
}

\author{
C. Paorici, C. Pelosi
}

\section{To cite this version:}

C. Paorici, C. Pelosi. Vapour phase chemical transport properties of the cadmium telluride-iodine system. Revue de Physique Appliquée, 1977, 12 (2), pp.155-159. 10.1051/rphysap:01977001202015500 . jpa-00244136

\section{HAL Id: jpa-00244136 https://hal.science/jpa-00244136}

Submitted on 1 Jan 1977

HAL is a multi-disciplinary open access archive for the deposit and dissemination of scientific research documents, whether they are published or not. The documents may come from teaching and research institutions in France or abroad, or from public or private research centers.
L'archive ouverte pluridisciplinaire HAL, est destinée au dépôt et à la diffusion de documents scientifiques de niveau recherche, publiés ou non, émanant des établissements d'enseignement et de recherche français ou étrangers, des laboratoires publics ou privés. 


\title{
VAPOUR PHASE CHEMICAL TRANSPORT PROPERTIES OF THE CADMIUM TELLURIDE-IODINE SYSTEM
}

\author{
C. PAORICI and C. PELOSI \\ Laboratorio MASPEC-CNR, Via Spezia, 73 43100-Parma, Italy
}

\begin{abstract}
Résumé. - On a étudié les possibilités de croissance de cristaux par transport en phase gazeuse du système CdTe : $I_{2}$. En comparant les taux de transport trouvés expérimentalement à ceux calculés à partir d'un modèle à 3 réactions, on a pu montrer qu'aucun transport d'iode n'est possible en tube scellé dans la direction allant de la zone chaude vers les régions plus froides, seul un transport par voie gazeuse contrôlé par la sublimation de la source est possible. Des plaquettes de grandes surfaces peuvent croître sur la charge constituant la source lorsque les gradiants de température sont faibles. Leur formation a été attribuée à un transport d'iode allant à contre-sens (froid-chaud) associé à une réduction de la sublimation des facettes cristallisées par rapport à la poudre constituant la charge.
\end{abstract}

\begin{abstract}
The vapour phase chemical transport properties of the CdTe : $I_{2}$ system have been investigated. By comparing the experimental transport rate with the theoretical transport rate calculated on the basis of a three reaction transport model, it was shown that no iodine chemical transport is possible in closed tubes in the hot-cold direction, but only vapour phase transport controlled by the source sublimation. Thin platelets with large smooth surfaces were observed growing on the source charge under small temperature gradients. Their growth was explained in terms of a reverse (cold-hot) iodine transport associated with a reduced sublimation tendency of the facetted crystallized material with respect to the unfacetted powdered material of the charge.
\end{abstract}

1. Introduction. - CdTe crystals can be grown from the vapour phase by means of chemical transport reactions [1-5] such as

$$
\text { CdTe (s) }+2 \mathrm{HX}(\mathrm{g})=\mathrm{CdX}_{2}(\mathrm{~g})+\mathrm{H}_{2}(\mathrm{~g})+0.5 \mathrm{Te}_{2}(\mathrm{~g})
$$

(where $\mathrm{X}=\mathrm{Cl}, \mathrm{Br}, \mathrm{I}$ ), provided that the thermodynamic conditions are chosen so that the tellurium partial pressure is maintained below its saturated value. This is necessary for avoiding liquid phase formation. In this case CdTe growth by SLV techniques could in principle be possible. However such a possibility was not tested by the authors.

By a suitable choice of overall pressure $(P)$, source and deposition temperatures $\left(T_{\mathrm{s}}, T_{\mathrm{d}}\right)$ and hydrogen-tohalogen atomic density ratio $(\mathrm{H} / \mathrm{X})$, broad zones can be defined in the $\mathrm{Cd}: \mathrm{Te}: \mathrm{H}: \mathrm{X}$ systems where the chemical transport only involves solid-vapour phase transitions.

The study of $\mathrm{Cd}: \mathrm{Te}: \mathrm{H}: \mathrm{X}$ systems is of particular interest because they offer the possibility of CdTe epitaxial deposition in open [1] as well as closedtube [6] arrangements.

As for the growth of large single crystals for applications, these systems do not seem particularly suitable, unless a better control of the initial nucleation can be achieved. Briefly reviewing this subject : crystals grown in closed tubes $[3,5]$ by $\mathrm{HCl}$ or $\mathrm{HBr}$ transport (gaseous $\mathrm{HCl}$ and $\mathrm{HBr}$ were obtained by thermal decompusition of the corresponding ammonium halides) are generally (111)-oriented platelets (maximal size : $10 \times 5 \mathrm{~mm}^{2}$ in surface area, $20-200 \mu \mathrm{m}$ thick). X-ray topography has shown [7] that the platelets are twinned crystals, beirig related by a $180^{\circ}$ rotation around [111] axis. Dendritic formations are generally present, indicative of constitutional supercooling in the vapour phase, while the dislocation density is very low. When using $\mathrm{H}_{2}+\mathrm{I}_{2}$ mixtures as transport agents, the crystal morphology is no longer bidimensional : welldeveloped polyhedra (maximal size : $12 \times 10 \times 5 \mathrm{~mm}^{3}$ ) with smooth faces as a rule are obtained [4].

When only iodine is used as a transport agent the $\mathrm{Cd}: \mathrm{Te}: \mathrm{I}$ system is the limiting case where $(\mathrm{H} / \mathrm{I})=0$. As has already been shown [4], a narrow zone exists, at high temperature and low pressure, where the tellurium partial pressure is not saturated. In this paper a thermodynamic characterization of this system will be presented, in view of its possible application for crystal growth and epitaxial deposition. In particular, preliminary experimental results will be discussed by taking into account the vapour phase kinetics of the system.

2. Thermodynamic properties of the Cd : Te : I system. - The main gaseous species which constitute the vapour phase are : $\mathrm{Cd}(\mathrm{g}), \mathrm{Te}_{2}(\mathrm{~g}), \mathrm{I}_{2}(\mathrm{~g}), \mathrm{I}(\mathrm{g})$, $\mathrm{CdI}_{2}(\mathrm{~g})$. Other possible species, such as $\mathrm{Te}(\mathrm{g})$, $\mathrm{TeI}_{2}(\mathrm{~g}), \mathrm{TeI}_{4}(\mathrm{~g})$, can be ruled out. In the presence of 
TABLE I

Reaction

$\Delta G(\mathrm{cal} / \mathrm{K}$ mol $)$
$14430-21.29 \mathrm{~T}$
$-21770-1.59 \mathrm{~T}+1.518 \mathrm{~T} \log T$
$68640-44.94 \mathrm{~T}$
$104840-64.64 \mathrm{~T}-1.518 \mathrm{~T} \log T$

Comments and references

$\Delta G_{3}+\Delta G_{4}$ in ref. [4]

$\Delta G_{3}+\Delta G_{4}-\Delta G_{5}$ in ref. [4]

$\Delta G_{3}$ in ref. [4]

$\Delta G_{3}+\Delta G_{5}$ in ref. [4] a solid phase constituted by stoichiometric CdTe, three independent heterogeneous equilibria can be written :

$$
\begin{array}{ll}
\mathrm{CdTe}(\mathrm{s})+\mathrm{I}_{2}(\mathrm{~g}) & =\mathrm{CdI}_{2}(\mathrm{~g})+0.5 \mathrm{Te}_{2}(\mathrm{~g}) \\
\mathrm{CdTe}(\mathrm{s})+2 \mathrm{I}(\mathrm{g}) & =\mathrm{CdI}_{2}(\mathrm{~g})+0.5 \mathrm{Te}_{2}(\mathrm{~g}) \\
\mathrm{CdTe}(\mathrm{s}) & =\mathrm{Cd}(\mathrm{g})+0.5 \mathrm{Te}_{2}(\mathrm{~g}) .
\end{array}
$$

If complete equilibrium is assumed between solid and vapour phases, the partial pressures of the gaseous species can be calculated for any given pressure and temperature, by solving the following set of equations :

$$
\begin{gathered}
P=\sum_{i} P_{i} \quad(i=1,2, \ldots 5 ; \text { gaseous species }) \\
K_{m}=\prod_{i} P_{i}^{q_{\mathrm{tm}}} \quad(m=1,2,3 ; \text { chemical reactions }) \\
(\mathrm{Cd} / \mathrm{Te})=\sum_{i} v_{i_{\mathrm{Cd}}} P_{i} \sum_{i} v_{i \mathrm{Te}} P_{i}=1
\end{gathered}
$$

where eq. (4) expresses Dalton's law ; eq. (5) gives the equilibrium constant of the $m$-th chemical reaction (the values of $K_{m}$ are easily obtained from the free-energy variations given in table I as a function of the temperature) ; $q_{i m}$ is the reaction coefficient of the $i$-th species in the $m$-th reaction; $(\mathrm{Cd} / \mathrm{Te})$ is the cadmium-totellurium atomic density ratio in the vapour phase, which is assumed to be unity : $v_{i \mathrm{Cd}}$ and $v_{i \mathrm{Te}}$ are the stoichiometric coefficients of $\mathrm{Cd}$ (respectively $\mathrm{Te}$ ) in the $i$-th molecule.

In reality, solid CdTe is not exactly stoichiometric [8], but the entire homogeneity range lies so close to the stoichiometric composition that deviations of no more than a few parts in 10 are to be expected in the (CdTe) ratio between the two phases. This fact justifies our assumption $(\mathrm{Cd} / \mathrm{Te})=1$, in eq. (6).

This set of equations has been solved by numerical methods. In figure $1, P$ and $P_{i}$ values are reported against the initial amount of iodine, $C_{\mathrm{I}}^{0}$, introduced into the system, when $T_{\mathrm{s}}$ and $T_{\mathrm{d}}$ are 1223 and $1173 \mathrm{~K}$ respectively. $C_{\mathrm{I}}^{0}$ is a function of $P$ and the average temperature given by the relationship :

$$
C_{\mathrm{I}}^{0}=\frac{2.4 \times 10^{5}}{R \bar{T}} \sum_{i} v_{i \mathrm{I}} \bar{P}_{i}(P) \quad\left(\mathrm{mg} / \mathrm{cm}^{3}\right)
$$

where $2 \bar{T}=T_{\mathrm{s}}+T_{\mathrm{d}} ; 2 \bar{P}_{i}=P_{i}\left(T_{\mathrm{s}}, P\right)+P_{i}\left(T_{\mathrm{d}}, P\right)$; $v_{i \mathrm{I}}$ is the stoichiometric coefficient of $\mathrm{I}$ in the $i$-th molecule.

The function $P=P\left(C_{\mathrm{I}}^{0}\right)$ is graphically represented in figure 2 for some values of $T_{\mathrm{s}}$ and $T_{\mathrm{d}}$.

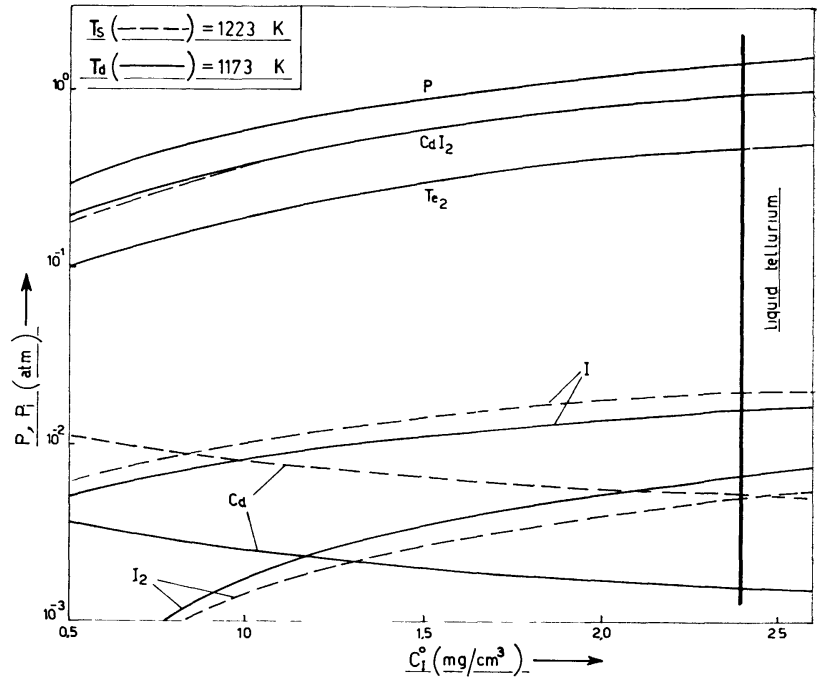

Fig. 1. - Overall pressure and partial pressures as a function of the initial iodine concentration. Solid lines : partial pressures at the deposition temperature. Dashed lines : partial pressures at the source temperature. The two curves for $\mathrm{Te}_{2}(\mathrm{~g})$ are practically coincident.

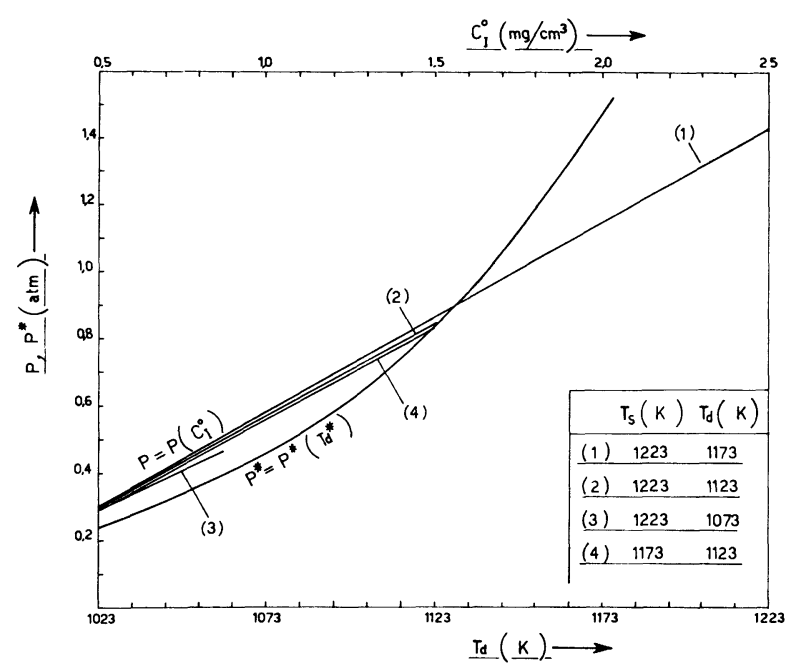

FIG. 2. - See text. The function $P^{*}=P^{*}\left(T_{\mathrm{d}}\right)$ is practically the same for $1173 \mathrm{~K} \leqslant T_{\mathrm{s}} \leqslant 1223 \mathrm{~K}$.

For a given source temperature $T_{\mathrm{s}}$, a liquid phase is expected to form at temperatures lower than $T_{\mathrm{d}}$ and pressures higher than $P$, where $T_{\mathrm{d}}$ and $P$ are defined by :

$$
P_{\mathrm{Te}_{2}}\left(T_{\mathrm{s}}, T_{\mathrm{d}}^{*}, P^{*}\right)=P_{\mathrm{Te}_{2} \text { (saturated) }} \text {. }
$$

In writing down eq. (8), the liquid phase was assumed 


\section{TABLE II}

Klosse and Ullersma's ratio for $T_{\mathrm{s}}=1223 \mathrm{~K}, L=18 \mathrm{~cm}$, for various values of $T_{\mathrm{d}}, P$, and the internal diameter $(d)$ of the ampoule in $\mathrm{cm}$

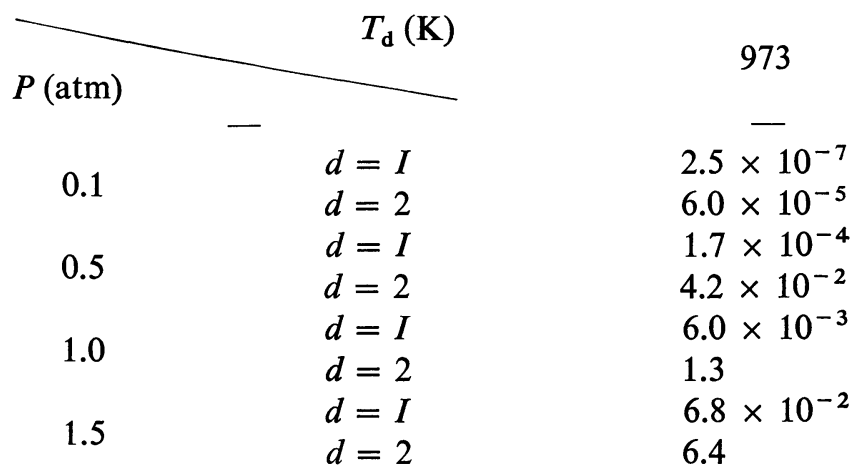

$$
1073
$$

-
$1.8 \times 10^{-7}$
$4.3 \times 10^{-5}$
$8.9 \times 10^{-5}$
$2.1 \times 10^{-2}$
$1.4 \times 10^{-3}$
0.32
$9.5 \times 10^{-3}$
1.9

$1.2 \times 10^{-7}$

$3.0 \times 10^{-5}$

$6.0 \times 10^{-5}$

$1.4 \times 10^{-2}$

$7.4 \times 10^{-4}$

0.17

$3.7 \times 10^{-3}$

0.83

1173 to be given by pure tellurium, and that no supersaturation is required for the vapour-liquid phase transition.

In figure $2, P^{*}=P^{*}\left(T_{\mathrm{d}}\right)$ is also reported. As it can be seen, this function is practically the same for $1173 \leqslant T_{\mathrm{s}} \leqslant 1273 \mathrm{~K}$.

3. Experimental part. - The following chemical transport experiments were carried out with iodine in a zone of $T_{\mathrm{s}}, T_{\mathrm{d}}$ and $P$ where no liquid phase is expected.

a) About $1 \mathrm{~g}$ of $99.999 \%$ pure CdTe powders, previously annealed under low $\mathrm{Cd}$ pressure to fix the stoichiometry, was placed in quartz ampoules, $18 \mathrm{~cm}$ long and $1 \mathrm{~cm}$ in inner diameter. Various amounts of iodine, such as to give overall pressures between 0.2 and $1.4 \mathrm{~atm}$. when $T_{\mathrm{s}}=1223 \mathrm{~K}$ and $T_{\mathrm{d}}=1773 \mathrm{~K}$, were distilled under vacuum into the ampoules. The ampoules were subsequently sealed off and placed in a horizontal tubular furnace. The required temperature profile was imposed for about 70 hours.

In all the experiments, polycrystalline boules, consisting of single crystal grains, were obtained. The grains apparently seem to have the [111] axis always in the direction of the ampoule axis; the exposed surfaces of the boules look rounded and smooth.

The source material is almost always completely sintered and the exposed surface is never facetted. Large single crystal portions are formed by coalescence in the sintered charge. The transport rate for each run is given in figure 3.

b) By maintaining $T_{\mathrm{d}}=1173 \mathrm{~K}$ and $C_{\mathrm{I}}^{0}=1 \mathrm{mg} / \mathrm{cm}^{3}$, $T_{\mathrm{s}}$ was lowered at $1203 \mathrm{~K}$. The deposits now consist of a thick, unfacetted crust with rough external surface, while the source is much less sintered. A number of well developed platelets (111) oriented, are often grown on the charge. When working with large diameter ampoules, platelets with smooth, mirror-like surfaces up to $15 \times 5 \mathrm{~mm}^{2}$ areas could be obtained.

c) By maintaining $T_{\mathrm{s}}=1203 \mathrm{~K}$ and $C_{\mathrm{I}}^{0}=1 \mathrm{mg} / \mathrm{cm}^{3}$, chemical transport experiments were performed where

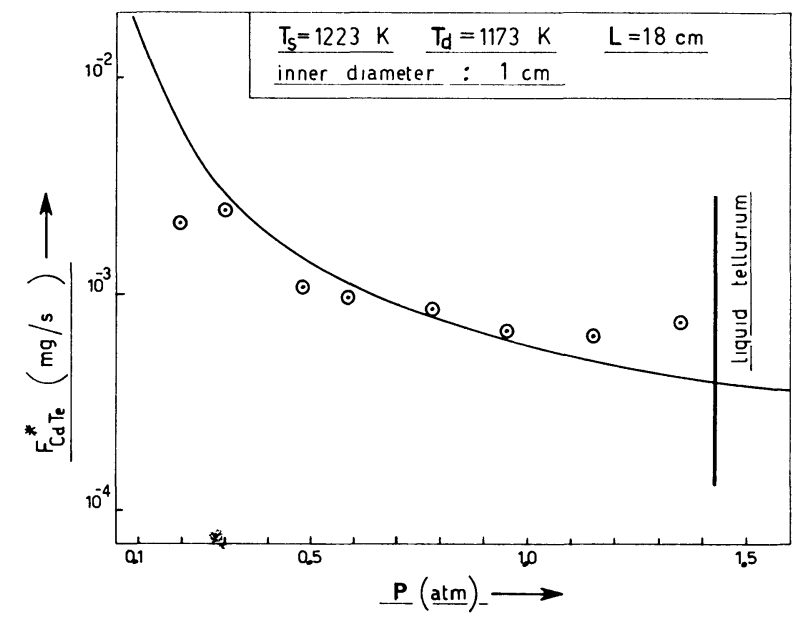

FIG. 3. - Net transport rate (theoretical and experimental) versus overall pressure.

$T_{\mathrm{d}}=1113,1093$ and $1053 \mathrm{~K}$ (at this last temperature a liquid phase is expected). What was observed is that the lower the $T_{\mathrm{d}}$, the smaller the number and size $o$ the platelets on the source, while facets, and occasio-

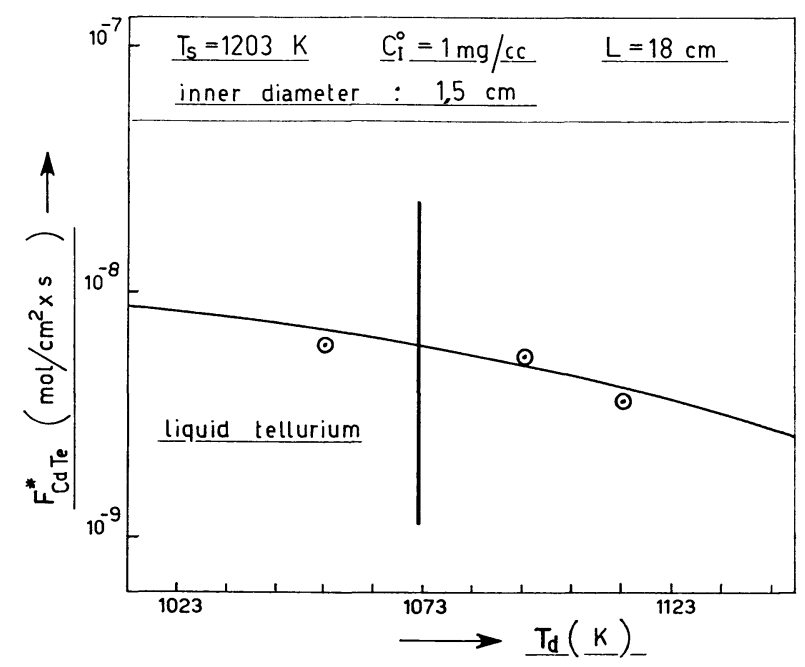

Fig. 4. - Net transport rate (theoretical and experimental) versus deposition temperature. 
nally some small crystal, are formed on the deposited material. The degree of sintering and coalescence of the source material is highly reduced.

Some transport rates as measured during these transport experiments are given in figure 4.

4. Discussion and conclusion. - A deposition process, such as the one we are interested in, is driven by gradients of the constitutional and thermal fields. Since the thermal equilibrium is reached very quickly, the driving force of the crystallization process is given, in practice, by the partial pressure gradients of the gaseous species. Two cases are to be considered: i) the actual partial pressures are very close to their equilibrium values, and consequently the growth process is controlled by the mass transfer through the vapour phase; ii) the actual partial pressures are higher than their equilibrium values, because of activational constraints at the growing interfaces : the growth process is controlled by surface processes. In the first case (the only one which can be quantitatively treated) for a three-reaction system such as ours, the CdTe transport rate can be expressed by :

$$
\begin{aligned}
F_{\mathrm{CdTe}}^{*}= & \frac{\Delta H_{\mathrm{I}} \Delta T(1+K)}{R R_{0} \bar{T}^{3} L} \times \\
& \times \frac{I+\alpha_{2}+\alpha_{3}}{\Phi_{\mathrm{II}}+\alpha_{2} \Phi_{22}+\alpha_{3} \Phi_{33}}\left(\mathrm{~mol} / \mathrm{cm}^{2} \mathrm{~s}\right)
\end{aligned}
$$

where $\Delta H_{\mathrm{I}}$ is the enthalpy change of reaction; $\Delta T=T_{\mathrm{s}}-T_{\mathrm{d}} ; R=82.06 \mathrm{~cm}^{3} \mathrm{~atm} / \mathrm{K} \mathrm{mol}$; $R_{0}=1.98 \mathrm{cal} / \mathrm{K} \mathrm{mol} ; L=$ ampoule length. $K$ is the ratio of the mass transfered by thermal convection to the mass transfered by concentration diffusion and Stefan flow (Klosse and Ullersma's ratio [9]). Some values of $K$ are reported in table II. It can be seen that for pressures lower than $1 \mathrm{~atm}$, and not too large $\Delta T$, the thermal convection does not contribute to the mass transfer, which is only given by concentration diffusion and Stefan flow. Finally, $\Phi_{m m}, \alpha_{2}$ and $\alpha_{3}$ are quantities defined in ref. [10]. These can be obtained from the terms of partial pressures, the binary diffusion coefficients of the various gaseous species and the enthalpy changes of reactions $(1,2)$ (for which $m=1,2)$ and

$$
\operatorname{CdTe}(\mathrm{s})+\mathrm{I}_{2}(\mathrm{~g})=\mathrm{Cd}(\mathrm{g})+2 \mathrm{I}(\mathrm{g})+0.5 \mathrm{Te}_{2}(\mathrm{~g})
$$

(for which $m=3$ in eq. (8) ; an easy application of Mandel's mathematical formalism necessitates the replacement of reaction (3) with a reaction such as (9), where gaseous iodine is present as a reactant species).

By using the suitable numerical values given in ref. [4], $F_{\mathrm{CdTe}}^{*}$ can be calculated and compared with the experimental results. As it can be observed in figures 3 and 4 , the vapour phase mass transfer process satisfactorily approximates the growth process.

The problems now to be solved are, first, by which transport mechanism (sublimation or chemical trans- port) the solid phase is transported and, secondly, what explanation can be given for the growth of platelets on the source.

If we consider the equilibrium reactions (1) and (2) as being responsible for the chemical transport, we observe (see Table I) that reaction (1) is endothermic $\left(\Delta H_{1}>0\right)$ while reaction (2) is exothermic $\left(\Delta H_{2}<0\right)$ : thus solid CdTe will be transported in opposite directions (from $T_{\mathrm{s}}$ to $T_{\mathrm{d}}$ according to reaction (I) and from $T_{\mathrm{d}}$ to $T_{\mathrm{s}}$ according to reaction (2)). Note that the laminar flow due to molecularity changes in the two reactions also enhances these two opposite masstransfer effects. Since for the two reactions, the freeenergy changes from $T_{\mathrm{s}}$ to $T_{\mathrm{d}}$ do not differ very much, the net transport rate of CdTe in either direction is expected to be rather small, of the order of magnitude of the transport rate due to CdTe source sublimation.

Sublimation and chemical-transport contributions can be quantitatively evaluated by taking into account the normalized transport rates, $Q_{i}$, of the single gaseous species, as defined by Arizumi and Nishinaga [11].

In the hypothesis that all the binary diffusion coefficients have the same value and that this average diffusion coefficient increases as the 1.8 power of $T$, the various $Q_{i}$ are given by the relationship :

$$
Q_{i}=\frac{T^{0.8}}{P}\left\{\Delta P_{i}-\frac{\bar{P}_{i} \sum v_{i \mathrm{I}} \Delta P_{i}}{\sum v_{i \mathrm{I}} \bar{P}_{i}}\right\}
$$

$Q_{i}$ values, positive when the mass transfer is in the hotcold direction and negative when in the opposite direction, are reported in figure 5 against $T_{\mathrm{d}}$ for $T_{\mathrm{s}}=1223 \mathrm{~K}$

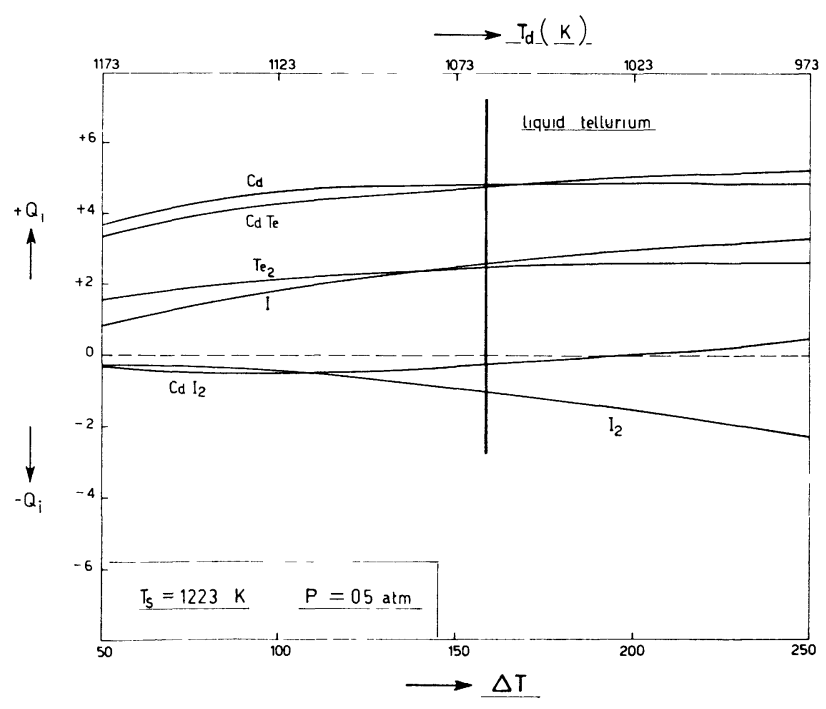

FIG. 5. - Normalized transport rates for single gaseous species and for CdTe versus undercooling.

and $P=0.5$ atm (a condition which approximates an iodine charge of $C_{\mathrm{I}}^{0}=1 \mathrm{mg} / \mathrm{cm}^{3}$ ). Since

$$
Q_{\mathrm{CdTc}}=Q_{\mathrm{Cd}}+Q_{\mathrm{CdI}_{2}}
$$

it is evident from the figure that the deposition of the boules at $T_{\mathrm{d}}$ is controlled by the source sublimation. 
No net chemical transport is possible in the hot-cold direction since $Q_{\mathrm{CdI}_{2}}<0$ in the whole liquid phase free zone. The fact that $Q_{\mathrm{CdI}_{2}}<0$ may yet give an explanation for the formation of platelets on the source, by supposing that $\mathrm{CdI}_{2}(\mathrm{~g})$ reacts on the chargé with $\mathrm{Te}_{2}$ (g) to give CdTe (s) with lamellar habit. Because of the large flat faces, and hence of the smaller evaporation coefficient [12], this morphology should withstand sublimation better than the powdered charge material. When $\Delta T$ is sufficiently small, a net amount of depo- sited CdTe on the source will result from the difference between deposition rate (from $\mathrm{CdI}_{2}+\mathrm{Te}_{2}$ ) and resublimation rate, thus giving rise to the platelet growth. When $\Delta T$ is increased by lowering $T_{\mathrm{d}}$ the resublimation rate turns out to be so high that $\mathrm{CdTe}$ deposition on the charge is no longer possible.

Acknowledgments. - The authors wish to thank Mr. G. Zuccalli for his technical assistance during the experimental work.

\section{References}

[1] Weinstein, M., Wolff, G. A. and Das, B. M., Appl. Phys. Lett. 6 (1965) 73.

[2] PAORICI, C., Proc. Intern. Symp. on CdTe, Strasbourg, 1971.

[3] Paorici, C., Attolini, G., Pelosi, C. and Zuccalli, G., J. Crystal Growth 18 (1973) 289 ; 28 (1975) 358.

[4] Paorici, C., Pelosi, C., Attolin, G. and Zuccalli, G., J. Crystal Growth 21 (1974) 227.

[5] Paorici, C., Pelosi, C., Attolin, G. and Zuccali, G., J. Crystal Growth 28 (1975) 358.

[6] Paorici, C., Pelosi, C. and Zuccalli, G., Phys. Stat. Sol. (a) 13 (1972) 95.

[7] Ghezzi, C. and PAorici, C., J. Crystal Growth 20 (1974) 58.
[8] Strauss, A. J., Proc. Intern. Symp. on CdTe, Strasbourg, 1971.

[9] Klosse, K. and Ullersma, P., J. Crystal Growth 18 (1973) 167.

[10] Jona, F. and Mandel, G., J. Phys. Chem. Solids 25 (1964) 187.

[11] Arizumi, T. and Nishinaga, T., Japan. J. Appl. Phys. 4 (1965) 165.

[12] Dettorre, J. F., KNorr, T. G. and Hall, E. H., in Vapour Deposition, C. F. Powell. J. H. Oxley and J. M. Blocher eds. (Wiley, New York and London) 1967. 